Research Article

\title{
Prediction Methods for Routine Maintenance Costs of a Reinforced Concrete Beam Bridge Based on Panel Data
}

\author{
Xiaoli Shi, ${ }^{1}$ Bingbing Zhao $\mathbb{D D}^{1}{ }^{1}$ Yuling Yao, ${ }^{1}$ and Feng Wang ${ }^{2}$ \\ ${ }^{1}$ School of Highway, Chang'an University, Xi'an 710064, China \\ ${ }^{2}$ Shaanxi Provincial Communication Construction, Xi'an 710075, China \\ Correspondence should be addressed to Bingbing Zhao; 617000203@qq.com
}

Received 12 February 2019; Revised 15 April 2019; Accepted 14 May 2019; Published 11 June 2019

Academic Editor: Heap-Yih (John) Chong

Copyright (c) 2019 Xiaoli Shi et al. This is an open access article distributed under the Creative Commons Attribution License, which permits unrestricted use, distribution, and reproduction in any medium, provided the original work is properly cited.

\begin{abstract}
In order to make informed decisions on routine maintenance of bridges of expressways, the hierarchical regression analysis method was used to quantify factors influencing routine maintenance cost. Two calculation models for routine maintenance cost based on linear regression and time-series analysis were proposed. The results indicate that the logarithm of the historical routine maintenance cost is the dependent variable and the bridge age is the independent variable. The linear regression analysis was used to obtain a cost prediction model for routine maintenance of a beam bridge, which was combined with the quantity and price, and verified by a physical engineering example. In order to cope with the cost changes and future demands brought about by the emergence of new maintenance technologies, the time-series analysis method was used to obtain a model to predict the engineering quantities for the routine maintenance of a bridge based on standardized minor repair engineering quantities. Taking into account the actual cost of the minor repair project as well as the time-series analysis' sample size demands, the annual engineering quantity was randomly decomposed into four quarterly data quantities, and the time-series analysis result was verified by physical engineering. These results can improve the calculation accuracy of the routine maintenance costs of reinforced concrete beam bridges. Furthermore, it can have a certain application value for improving the cost measurement module of bridge maintenance management systems.
\end{abstract}

\section{Introduction}

Maintenance cost planning is an important component of highway infrastructure asset management. In the classification system of highway maintenance engineering in China, routine maintenance has the characteristics of regularity, repeatability, and timeliness, as compared with medium maintenance, heavy maintenance, preventive maintenance, emergency maintenance, or special maintenance. It is the basic work of highway maintenance management and plays an important role in prolonging the periodic overhaul life and reducing the cost of road users $[1,2]$. The measurement and calculation of annual maintenance expenditures (AMEX) is an important module of an asset management system [3-8]. Figure 1 shows the valuable uses of AMEX prediction models [9-13].
The objects of the asset management of highway infrastructure involve subgrade, pavement, bridge and culvert, and tunnel and traffic facilities. The structural characteristics and working principles of each asset are quite different, so each should be treated differently in the process of management and maintenance. Many scholars have devoted themselves to the study and development of the maintenance cost budget of the asset management of highway infrastructure. A large number of reports have focused on the calculation of routine maintenance. Most of the research methods are based on regression analysis, and the dependent variable is the routine maintenance cost $[9,14-24]$ or routine maintenance quantity [25]. According to the choice of independent variables, the approaches can be summarized into the following four categories: 


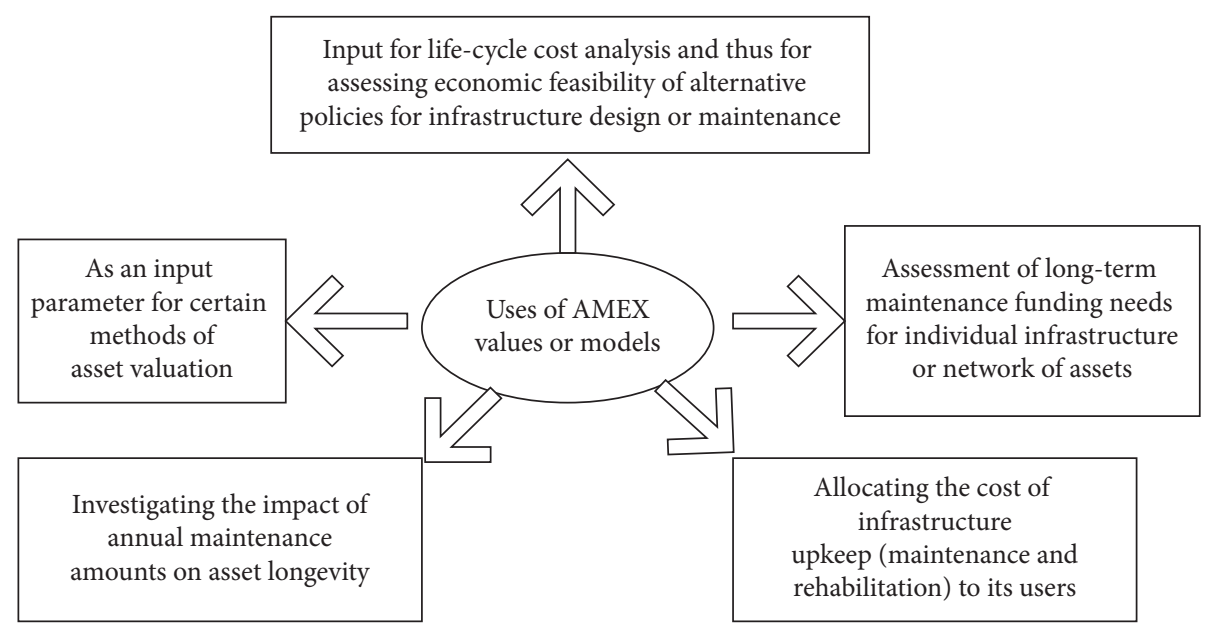

Figure 1: Uses of AMEX models.

(1) Using performance as an independent variable, for instance, Al-Mansour and Sinha [17] determined the regression equation of road annual routine maintenance cost and the pavement service performance index. Lu and Tolliver [18] determined the regression equation of annual routine maintenance cost and the international roughness index.

(2) Taking the natural environment, traffic environment, and road age as independent variables, the representative results are as follows: Hagood [19] concluded that the independent variables of five models of pavement routine maintenance cost in Nevada included the length of road section, area, road age, altitude, climate, temperature, cumulative equivalent axle load, and the cost of the previous year. The California pavement maintenance cost model studied by Gibby et al. [20] includes the annual average daily traffic (AADT) of heavy vehicles, AADT of passenger cars, road age, temperature, presence of shoulders, presence of bridges, and road area. Volovski et al. [21] considered the road age, AADT, average annual rainfall, length of the road, number of lanes, nature of the road (new or reconstructed pavement), and other factors when analyzing the cost of road maintenance in Indiana, USA. Qiu et al. [22] et al. constructed an indicator system of highway routine maintenance rates and considered six calculation variables such as AADT, annual average daily weight of vehicles, routine maintenance engineering amount, and special maintenance engineering amount.

(3) Considering both the road performance and the road technical conditions, Woldemariam et al. [9] used the ANN method to predict the cost of pavement maintenance. The input variables were annual average temperature, annual average rainfall, total network size, IRI, and truck vehicle-kilometers traveled. Wu [23] reported on the quantitative relationship between the annual maintenance cost of highway asphalt pavement in Zhejiang Province, China, as well as the pavement quality index (PQI), traffic volume, truck ratio, and operating life. Yue [25] summarized the influencing factors of damage maintenance amounts in the routine maintenance of asphalt pavement using pavement-engineering quality grade, width, thickness, performance index, service life after conversion, annual average daily heavy traffic (AADT), annual average rainfall, and annual average temperature difference.

(4) Directly providing the routine maintenance cost intervals without considering any independent variables: for instance, the US Highway Economic Requirements System State (HERS-ST) calculated that the average daily maintenance cost of a road unit length varies from $\$ 285$ to $\$ 7830$ per lane-kilometer. Ola and Ugiomoh [24] obtained the criteria of the annual maintenance cost of a road, which states that the cost of a paved two-lane rural main road is from $\$ 870 / \mathrm{km}$ to $\$ 1730 / \mathrm{km}$ and that the cost of a paved four-lane main road is from $\$ 1682 / \mathrm{km}$ to $\$ 6743 / \mathrm{km}$, and finally that that of a two-lane main road without paving is $\$ 703 / \mathrm{km}$ to $\$ 1407 / \mathrm{km}$. It is obvious that the notion of a cost interval is affected by various factors.

Research on the maintenance cost of bridge assets involves the preventive maintenance opportunity of a bridge based on a cost-benefit analysis [26], the maintenance cost model based on life-cycle cost [3-8, 27-32], the maintenance cost model [28] included in the development of bridge maintenance management systems $[5,6,33,34]$, and the research specifically on the prediction of bridge maintenance cost $[10,31,35-39]$. The factors influencing the maintenance cost of bridges are the same as those influencing the technical status of bridges [40-43]. Studies in the literature [44] have reported on analyses of the influence of bridge superstructure form, completion time, load grade, bridge length, and other factors. Other studies in the literature [45] have considered the influence of environment, bridge age, maintenance measures, and other factors when evaluating the technical status of bridges. The AADT, structure location, and other factors were taken into account when verifying the adaptability of a bridge deck in Maryland, USA. In 
the relevant literature [46-48], the influence of environmental and traffic factors on bridges was considered, respectively. In the research literature of Hegazy et al. [34], factors such as bridge deck type (steel bridge or concrete bridge), year, highway type (interstate highway or other), average daily traffic (ADT), width, length, and technical status were considered. In the report of Ali et al. [10], climatic factors (including annual average temperature and annual average rainfall), average daily truck traffic (ADTT), technical status, total bridge deck area of each state, average bridge deck area of each state, and other factors were considered.

The existing research can be summarized as follows:

(1) Transportation infrastructure maintenance has obvious regional characteristics. Researchers analyzed the problem with a specific area as their research object [19-23].

(2) Most researchers concentrate on pavement maintenance costs because this constitutes the largest portion of the road maintenance cost, but they concentrate less on the study of bridge maintenance cost.

(3) Factors affecting the asset condition should be taken into account in the calculation of the maintenance cost of pavement and bridges. Different scholars consider different influencing factors in different periods. In particular, traffic influencing factors, such as $\mathrm{AADT}$, ESAL, heavy-truck AADT, and heavytruck ratio, are considered. They all choose a certain factor directly and do not provide a basis for selecting the corresponding factor.

(4) There are more studies to be found on repair expenditure [10], preservation expenditure $[14,35,36]$, or maintenance expenditure specifically [9], but fewer studies on routine maintenance $[15,16,23,25]$ or daily maintenance costs.

We believe that there are significant differences between different types of maintenance-implementation occasion and implementation content, while routine maintenance engineering has the characteristics of regularity, and the corresponding cost must be paid every year. Therefore, there is both theoretical and practical significance to focus study on maintenance engineering. This paper draws lessons from an idea that is based on the research on the routine cost of pavement maintenance. The data in this paper are derived from the historical routine maintenance cost and details of reinforced concrete (RC) beam bridges since the opening of the 11 expressways in Shaanxi Province. With the aim of setting research boundary conditions and adopting quantitative analysis methods, the influencing factors of routine maintenance cost of this type of bridge asset are selected and determined. Based on these, this paper puts forward two calculation methods: the regression model with routine maintenance cost as the dependent variable, and the prediction model with routine maintenance details as the dependent variable. Their respective applicable conditions are delineated, which are verified by physical engineering.
In this paper, the routine maintenance tasks for reinforced concrete beam bridges include the maintenance of drainage facilities, expansion joints, abutment, the maintenance of guardrails, antithrowing nets, expansion devices, and drainage facilities. Among these items, the maintenance of the guardrail involves painting for concrete guardrails and rust-removing paint for the handrails. The maintenance of the antithrowing mesh refers to replacing the pillars and bases of the antithrowing mesh. The maintenance of expansion devices involves repairing the concrete, replacing rubber strips, and welding the steel of expansion joints. Maintenance of drainage facilities involves replacing the centralized drainage pipe of a bridge, replacing the four-way base of PVC and repairing the cover of the drainage hole.

\section{Materials and Methods}

2.1. Setting Boundary Conditions. Expressway routine maintenance costs are affected by a number of factors. Quantitative studies on their cost investment are required to limit the boundary conditions, which include the following.

2.1.1. Delimiting "Special Service Supply Level". In the current maintenance management system of China, different maintenance types influence each other along the same highway. The cost of small repairs and their quality of implementation affects the timing of preventive maintenance. The implementation effect of preventive maintenance affects the time required for large and medium repairs and whether timely preventive maintenance and overhaul will affect routine maintenance expenditures. To maintain an expressway's operating service level, the expressway operating company sets a minimum acceptable level for the performance indicators of the expressway assets. This paper defines this level as the level of maintenance-service supply. The maintenance costs reflected by different levels of maintenance-service supply levels vary. Therefore, it is necessary to set the boundary conditions of the maintenance-service supply level to ensure that bridge assets have the same maintenance-service level. In this case, the research is valuable in practical applications.

2.1.2. Climate and Environmental Factors Normalized to Regional Factors. In the course of evaluating the assets of expressway bridges, it is important to note that they are influenced by natural environmental factors. This paper normalizes these natural environmental factors into regional factor variables. In other words, bridge assets located in the same area are situated in the same range of temperature variation, precipitation, and altitude. In this research, bridge assets located in the same climate region are treated as a group of analysis objects.

2.1.3. Traffic Factor Indicators. Traffic volume factors can be reflected by the AADT, heavy-truck ratio, ESAL, and cumulative ESAL. In the literature, different scholars have selected various different indicators of traffic volume. 
To determine the traffic factors affecting the cost of routine maintenance of bridge assets scientifically and reasonably, this paper divides the traffic volume indicators into the following categories: AADT (hereinafter referred to as traffic volume indicator 1), AADT + heavy-truck volume (hereinafter referred to as traffic volume indicator 2), $\mathrm{AADT}+$ heavy-truck ratio (hereinafter referred to as traffic volume indicator 3), ESAL (hereinafter referred to as traffic volume indicator 4), and $\sum$ ESAL (hereinafter referred to as traffic volume indicator 5),

Using the above, the appropriate traffic indicator is determined by quantitative analysis.

2.1.4. Years of Usage. Due to the different opening years of each highway project, the analysis converts the different opening years into bridge age and uses the same number of years of traffic in the same area as a set of sample data.

2.1.5. Road Segmentation. This paper takes the expressway in Shaanxi Province, China, as the analysis object. According to the management system of Shaanxi Province, a specific branch is responsible for the operational management of each expressway. The maintenance budget is also formulated on the basis of each individual expressway. This paper uses the historic cost data of each operating branch of the expressway for the underlying analysis. As a result, this work considers a highway managed by each branch as a specific analysis object. The maintenance management level of each branch is influenced by the maintenance policy of the central office, and each branch is under the unified jurisdiction of the group company. Therefore, the maintenance-service supply level of each branch is the same.

\subsection{Study Methodology}

2.2.1. Applicability of Multivariate Regression Analysis Methods. Multiple regression analysis can be used for predictive regression as well as interpreted regression [49]. Predictive regression can be used to predict the trend of the dependent variables, where the interpreted regression mainly focuses on the relationship of the variables. This interpreted regression meets the needs of this paper. The influencing factors of this study have continuous variables, such as years of usage and traffic volume, and also include categorical variables, such as regional factors. When there are categorical variables in a multiple regression analysis, the method requires hierarchical regression analysis [50], which satisfies the requirements of analyzing multiple influencing factors. At the same time, the available mathematical tools can be used to judge the degree of influence of each factor on the routine maintenance of each asset.

\subsubsection{Preprocessing of Variables}

(1) Preprocessing of Dependent Variables. In the analysis, the total routine maintenance investment for each bridge is taken as the dependent variable (interpreted variable). The total cost includes the sum of the daily cleaning and routine maintenance under the boundary conditions of an identical level of maintenance-service supply. Because the routine maintenance cost of each asset is affected by the size of the bridge $[9,10,14,34]$ and the year of implementation, this research adopts the following methods:

(1) In order to eliminate the impact of the asset scales on the routine maintenance costs, the annual actual cost of each asset is standardized by equation (1).

(2) In order to eliminate the impact of price factors of manpower, materials, and machinery in different opening years, the routine maintenance cost data for different years are converted into the cost value of the base year (2015) with price indices. In other words, $\mathrm{TC}_{i t}$ in equation (1) is the routine maintenance cost that is converted into the base year:

$$
C_{i t}=\frac{\mathrm{TC}_{i t}}{n_{i k} \cdot L_{i k}},
$$

where $C_{i t}$ is the routine maintenance cost per lane-kilometer in the $t$ year of road bridge $i$ (yuan/lane. $\mathrm{km}$ ), $\mathrm{TC}_{i t}$ is the routine maintenance cost in the $t$-year of road bridge $i$ (yuan), $n_{i k}$ is the number of $k$ th lanes of road $i$ (usually 4,6 , or 8 lanes), and $L_{i k}$ is length of the road $i$ in the lane $k(\mathrm{~km})$.

In introductory econometrics, when the dependent variable is positive and the unit is yuan, the logarithm is given to the dependent variable first, using $\log _{10} C_{i t}$ as the dependent variable. The logarithm can eliminate or reduce the skewness of the mathematical distribution of the dependent variable and can narrow its range. This brings it closer to the classical, linear model assumption instead of the direct use of $C_{i t}$ as the dependent variable. In this study, the calculation results of equation (1) are taken as the dependent variable after taking the logarithm.

(2) Preprocessing of Independent Variables. The independent variables used in this paper include traffic volume, regional factors, and age. They also include factors of scale involving the length, width, and area of bridges $[10,34]$ because the historical data are accumulated for each road, and it is impossible to identify the cost of the bridges of different scales on the road; hence, such factors are not included in the independent variables. The regional factor in the independent variable is the category variable, and the other two factors are continuous variables. The most important hypothesis in multiple regression analysis is the linear relationship hypothesis. This requires that the independent variables in the model must be continuous, and further indicates that the categorical variables are not suitable for multiple regression analysis [50]. In reality, the categorical variables are extremely important. In order to enable the use of the regional factors in the regression analysis with other continuous variables, it is necessary to virtualize the categorical variables. This requires that the categorical variables be converted into dummy variables first.

The key step to virtualize the categorical variables is the recoding of them. Usually, the recoding method employs 
virtual coding, which converts the categorical variables into 0 and 1 dichotomous variables. After conversion, the dummy variables can be taken as source data into the multiple regression equation for regression analysis, similar to that for the other continuous variables. When the type of the categorical variable is $k$, the virtualized categorical variables need to be split into $k-1$ virtual variables. These can then be used in the hierarchical regression analysis function module in a statistical software package to input the entire set of $k-1$ dummy variables into the multiple regression analysis.

There are three regional variables analyzed in this paper as categorical variables: Shanbei, Guanzhong, and Shannan. When virtualizing these three categorical variables, one first must choose a reference group. This study regards Shannan as the reference group, which enables the division of the three categorical variables into two dummy variables.

(3) Independent Variable Classification and Order. When there are categorical variables in a multiple regression analysis, the best choice is the hierarchical regression analysis [50]. In the hierarchical regression analysis, one first groups the independent variables and then brings the independent variables into the multiple regression equations in the order of grouping. In this paper, the hierarchical group is classified as follows: the regional variable is used as group 1; the age is taken as group 2; and the traffic volume indicator is used as group 3. It should be noted that, for traffic volume indicators 1 through 4 and for traffic volume indicator 5, only a single traffic volume indicator can be input at a given time for hierarchical regression analysis.

\subsection{Parametric Analysis Using Multivariate Regression}

2.3.1. Multivariate Regression Analysis Models and Indicators. The multivariate hierarchical regression model is shown in the following equation:

$$
\log _{10}^{C_{i t}}=a+b_{1} x_{1}+b_{2} x_{2}+b_{3} x_{3},
$$

where $C_{i t}$ is the routine maintenance cost per lane-kilometer in the $t$-year of road bridge $i$ (yuan/lane. $\mathrm{km}$ ), $x_{1}$ is the regional factor variable (Shanbei, Guanzhong, and Shannan), $x_{2}$ is the age, and $x_{3}$ is the traffic volume indicator.

Regression coefficient $b_{i}$ indicates the interpretation degree of the corresponding independent variable $x_{i}$ for the dependent variable $\log _{10} C_{10}$. The regression coefficient is a nonstandardized statistical parameter with units. Although it can reflect the number of influences of the corresponding variables of the independent variable, it cannot convincingly indicate the importance of each independent variable according to their sizes. Therefore, it cannot be used for comparison purposes. If one wants to compare the regression coefficients and get a more intuitive interpretation of each independent variable against the dependent variables, all variables in equation (2) can be standardized by calculating $Z$ scores; the intercept term $a$ disappears. Equation (2) then becomes equation (3), and it is then very straightforward to judge the interpretation degree of independent variables for various dependent variables. $\beta_{j}$ in equation (3) is defined by equation (4):

$$
\begin{aligned}
Z_{\log _{10}^{c_{i t}}} & =\beta_{1} z_{1}+\beta_{2} z_{2}+\beta_{3} z_{3}, \\
\beta_{j} & =b_{j} \frac{s_{x_{j}}}{s_{\log _{10}^{c_{i t}}}},
\end{aligned}
$$

where $s_{x j}$ is the standard deviation of the $j$ th independent variable $x_{j}$ and $S_{\log _{i t}}$ is the standard deviation of dependent variables $\log _{10} C_{\text {it }}$ after taking the logarithm.

\subsubsection{Analysis Content and Criteria for Assessing the} Influencing Factors. The purpose of the regression analysis in this paper is to explore the interpretation degree of independent variables against the dependent variables. Therefore, the overall explanatory power, $R^{2}$, of the model is reported first. The statistical significance of $R^{2}$ is explained by the test data of the $\mathrm{F}$ test. In the process of hierarchical regression analysis, when a variable enters the group to participate in the regression analysis before other variables, the first variable plays the role of the control variable in the group, while the subsequent variables are added. $\Delta R^{2}$ represents the additional explanatory power that the group is dedicated under the influence of the previous set of variables. When $\Delta R^{2}$ is as large as possible and $\Delta p$ reaches statistical significance, it is considered that the addition of the group can effectively enhance the explanatory power of the model.

The research focuses next on the standardized coefficient. In Tables 1 and 2, each independent variable has a corresponding standardized regression coefficient, the $\beta$ coefficient, and a significance test result. Standardizing the regression coefficient can unify the units of each independent and dependent variable and reduce the error caused by conflicting units, making the results more accurate.

For the $\beta$ coefficient, the larger the absolute value of the $t$ test is, the smaller the $p$ value becomes. The $p$ value indicates the significance of the $t$-test. In statistics, if $p<0.05$, then the coefficient test is generally considered to be significant, indicating that the independent variable can effectively predict the variation of the dependent variable. In the $p=$ 0.05 case, the possibility of an incorrect conclusion is $5 \%$ and that of a correct one is $95 \%$.

In the coefficient table of regression analysis results, the $\beta$ coefficient can be positive or negative. This reflects that the standard deviation-led by the doubling of an independent variable-causes the standard deviation of the dependent variable to increase by the multiple (or decrease by the fraction) of the absolute value of $\beta$, respectively. A larger absolute value of $\beta$ of an independent variable means that the independent variable affects the dependent variable to a greater degree. Therefore, in this paper, we only focus on the absolute value of $\beta$.

Based on the regression analysis results of all the models and the actual scenario, this paper addresses whether an independent variable can be the main influencing factor of routine maintenance cost. The result is as follows: 
TABLE 1: Hierarchical regression analysis results of the RC beam bridge.

\begin{tabular}{|c|c|c|c|c|c|c|c|c|c|c|}
\hline \multirow{2}{*}{\multicolumn{2}{|c|}{ Variables in the model }} & \multicolumn{3}{|c|}{ Group 1} & \multicolumn{3}{|c|}{ Group 2} & \multicolumn{3}{|c|}{ Group 3 (1) } \\
\hline & & $\beta$ & $t$ & $p$ & $\beta$ & $t$ & $p$ & $\beta$ & $t$ & $p$ \\
\hline \multirow{4}{*}{ Independent variables } & Shanbei & 0.02 & 0.099 & 0.922 & 0.128 & 0.785 & 0.439 & 0.22 & 1.136 & 0.888 \\
\hline & Guanzhong & 0.002 & 0.012 & 0.991 & -0.071 & -0.442 & 0.662 & -0.051 & -0.311 & 0.265 \\
\hline & Age & & & & 0.631 & 4.174 & 0 & 0.606 & 3.921 & 0.758 \\
\hline & AADT & & & & & & & 0.161 & -0.137 & 0.001 \\
\hline \multirow{5}{*}{ Model summary of the model } & $R^{2}$ & & 0 & & & 0.375 & & & 0.393 & \\
\hline & Adjusted $R^{2}$ & & -0.066 & & & 0.311 & & & 0.306 & \\
\hline & $p$ & & 0.995 & & & 0.003 & & & 0.006 & \\
\hline & $\Delta R^{2}$ & & 0 & & & 0.375 & & & 0.017 & \\
\hline & $\Delta p$ & & 0.995 & & & 0 & & & 0.382 & \\
\hline
\end{tabular}

(1) When $\beta>0.30$ and the $p$ value is statistically significant, the explanatory variable is the main influencing factor.

(2) When $\beta>0.30$ and the $p$ value are not statistically significant, the result might be caused by insufficient sample data. However, the practical significance of the variable cannot be ignored, so the explanatory variable is also considered to be the main influencing factor.

(3) When $\beta$ is approximately 0.20 , it is necessary to assess the importance of the explanatory variable based on its practical significance. If it is of great practical significance, then it can be considered as the main influencing factor; if not, then it cannot be considered.

\section{Results and Discussion}

3.1. Analysis and Discussion of the Model Results. This paper analyzes 11 expressways managed by Shaanxi Provincial Communication Construction Group. The longest operation duration among them is 15 years, and the shortest is 3 years. According to the regional characteristics of Shaanxi Province, 11 highways are divided into those of three regions, namely, Northern, central, and Southern Shaanxi, which are taken as three independent variables of region. During research, we collected the routine beam bridge maintenance cost of all 11 expressways for each operation duration. Preprocessing of Dependent Variables shows the price index adjustment and normalization of the data. We take its natural logarithm as the dependent variable. Independent Variable Classification and Order classifies the independent variables into different groups and defines their time series for hierarchical regression analysis. The analysis results are shown in Tables 1 and 2, and Figure 2 shows the corresponding standardized regression coefficients.

From Tables 1 and 2, the following could be obtained:

(1) The explanatory capability of the overall model of all independent variables is visibly high, indicating that they can explain the change in the dependent variable.

(2) From the perspective of the individual explanatory capability of each hierarchy, the explanatory capability of Group 1 is relatively low, while that of Group 2 is significantly high $\left(\Delta R^{2}=0.375\right.$, $\Delta P=0.001)$. This demonstrates that taking into consideration the road-operation duration can effectively improve the explanatory capability of the model.

(3) The increment regression result of the traffic factor in Group 3 shows that the increment of any traffic factor has no statistical significance.

As shown in Figure 2, the values of the $\beta$ coefficient of operation duration are high in each group, remaining larger than 0.6 , and the $t$-test results are of high statistical significance. However, for other independent invariables, the $\beta$ coefficients are small and the $t$-test results are of no statistical significance.

Therefore, we conclude the analysis on the influencing factors of routine beam bridge maintenance costs as follows:

(1) Regarding the regional factor, there is no obvious difference in the routine beam bridge maintenance cost between Northern, central, and Southern Shaanxi.

(2) The road-operation duration has a strong explanatory capability and is statistically significant. Therefore, it can be an important influencing factor.

(3) For the five traffic factors, although the model reflects that they have great overall explanatory capability, the values of the $\beta$ coefficient are small and the statistical significances are low. As a result, the traffic volume indicators are considered to be unimportant influencing factors.

3.2. Calculation and Verification of Routine Maintenance Cost of the RC Beam Bridge. According to the analysis results of the influencing factors of routine RC beam bridge maintenance costs, the regression model of routine maintenance cost prediction can be established in two manners: first, routine maintenance cost is set as the dependent variable, and road-operation duration is set as the independent variable. Through regression analysis, their functional relation can be determined and then used to predict the annual maintenance cost in the future. Second, based on the analysis results of influencing factors and the time-series forecasting 


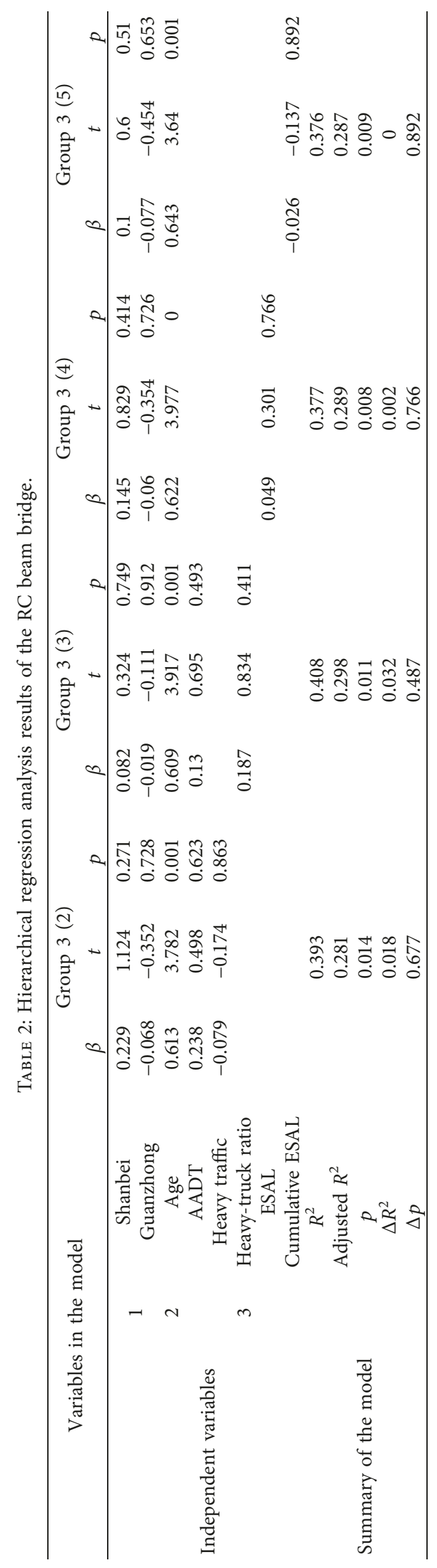




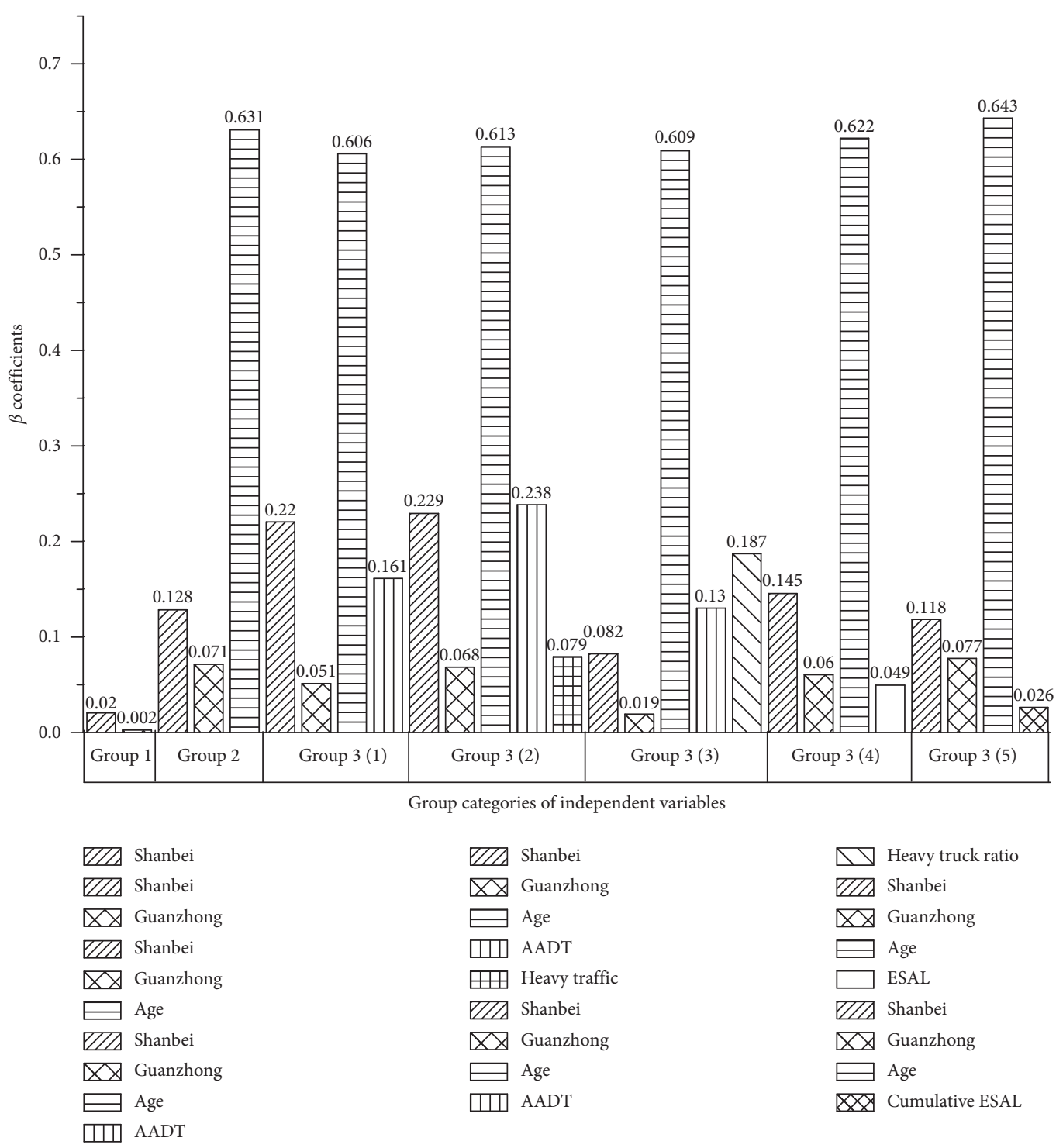

FIGURE 2: Standardized regression coefficients for RC beam bridge assets.

method, the amount of routine maintenance is taken as the dependent variable to predict its annual value in the future. In this way, according to the current maintenance quota, the cost can be calculated.

\subsubsection{Prediction and Verification of Routine Maintenance} Cost Based on Linear Regression. Here, we continue to use the data in the quantitative analysis on influencing factors, namely, the historical maintenance cost data (for 2015) after price index adjustment, standardization, and logarithm processing. It is set as the independent variable and expressed by $y$. The road operation duration (beam bridge age) is taken as the independent variable. The final regression formula is

$$
\log _{10}^{y}=3.5+0.015 \times \text { bridge age }\left(R^{2}=0.99\right) .
$$

To verify the formula accuracy, we compare the predicted value of the regression formula with the actual routine beam bridge maintenance costs in 2016 and 2017, as shown in Table 3. Data in the table are normalized to 2017 prices.

Nonparametric testing does not require samples to obey an assumption of normal distribution, so it is usually applied to the data test of a small-scale sample, classified data, and an ordinal number. As part of the double-correlation nonparametric test, the Wilcoxon signed-rank test meets the requirement of the consistency check between the predicted value and actual value in this study.

The Wilcoxon signed-rank test is a nonparametric hypothesis testing method. It checks the data in two data sets in pairs (a paired difference test) to determine whether the two data sets come from the same distributed collection.

The Wilcoxon signed-rank test, as a type of doublecorrelation sample test, is based on correlation detection. It analyzes the correlation between two groups of data first. When the correlation reaches a certain degree, the Wilcoxon signed-rank test is carried out. The test does not require the 
TABLE 3: Summary of actual and predicted costs based on nonlinear regression and test results.

\begin{tabular}{|c|c|c|c|c|c|c|}
\hline \multicolumn{2}{|c|}{ Project } & Age (years) & Bridge length $(\mathrm{km})$ & Number of lanes & Predicted value & Actual value \\
\hline \multirow{2}{*}{ Shang Man } & 2016 & 8 & 37.85 & 4 & 692160 & 424724 \\
\hline & 2017 & 9 & 37.85 & 4 & 721450 & 818112 \\
\hline \multirow{2}{*}{ Shang Jie } & 2016 & 9 & 45.34 & 6 & 1296322 & 1463289 \\
\hline & 2017 & 10 & 45.34 & 6 & 1351179 & 1998922 \\
\hline \multirow{2}{*}{ Xi Shang } & 2016 & 5 & 56.13 & 6 & 1359648 & 1845905 \\
\hline & 2017 & 6 & 56.13 & 6 & 1417186 & 1464380 \\
\hline \multirow{2}{*}{ An Chuang } & 2016 & 6 & 75.966 & 4 & 1278673 & 1233239 \\
\hline & 2017 & 7 & 75.966 & 4 & 1332784 & 1130645 \\
\hline \multicolumn{7}{|c|}{ Results of the Wilcoxon signed-rank test } \\
\hline \multicolumn{3}{|c|}{ Correlation coefficient } & \multicolumn{2}{|c|}{$\begin{array}{l}\text { Statistical significance of the correlation } \\
\text { coefficient }\end{array}$} & \multicolumn{2}{|c|}{$\begin{array}{l}\text { Statistical significance of the } \\
\text { Wilcoxon signed-rank test }\end{array}$} \\
\hline \multicolumn{2}{|l|}{0.83} & & \multicolumn{2}{|c|}{0.01} & \multicolumn{2}{|c|}{0.44} \\
\hline
\end{tabular}

samples to obey the assumption of normal distribution and is usually applied to test the data of small-scale samples.

In analysis of the result of the correlation coefficient, apart from the coefficient, the SIG value (namely, the $p$ value), which indicates the significance, also exists.

The original hypothesis of the Wilcoxon signed-rank test was that there is no significant difference between the predicted value and the actual value, and the alternative hypothesis was that they are different.

The test result shows that the predicted value is highly correlated with the actual value and is statistically significant, indicating the feasibility of the prediction formula.

\subsubsection{Prediction and Verification of the Engineering Quantity} of Routine Maintenance Based on Time Series. The cost prediction model built on nonlinear regression and logarithm processing makes a forecast on the basis of historical data. However, the reference value of historical data is severely affected owing to the impact of new materials, new technologies, and new equipment on cost. This is especially true for the period during which policy changed from business tax to VAT; the items of cost changed significantly. Therefore, considering the separation of quantity and price, the prediction of the engineering quantity of routine maintenance can not only eliminate the influence of new technology on cost forecasts but can also exempt the impact of new taxes and fee-pricing policies.

According to the analysis' results of influencing factors, the engineering quantity of $\mathrm{RC}$ routine beam bridge maintenance is affected by various natural and accidental factors which will gradually show a certain time characteristic in the long term. Time-series analysis is usually used to study and analyze a series of data arranged in an order. It can reveal the inherent law of the data and make short-term predictions. Therefore, this paper uses time-series prediction with the assistance of the SAS analysis software to study and make short-term predictions on the engineering quantity of $\mathrm{RC}$ routine beam bridge maintenance.

The modeling steps for time-series analysis are shown in Figure 3.

(1) Data Preprocessing. Data preprocessing in time-series analysis includes standardization of engineering quantities,

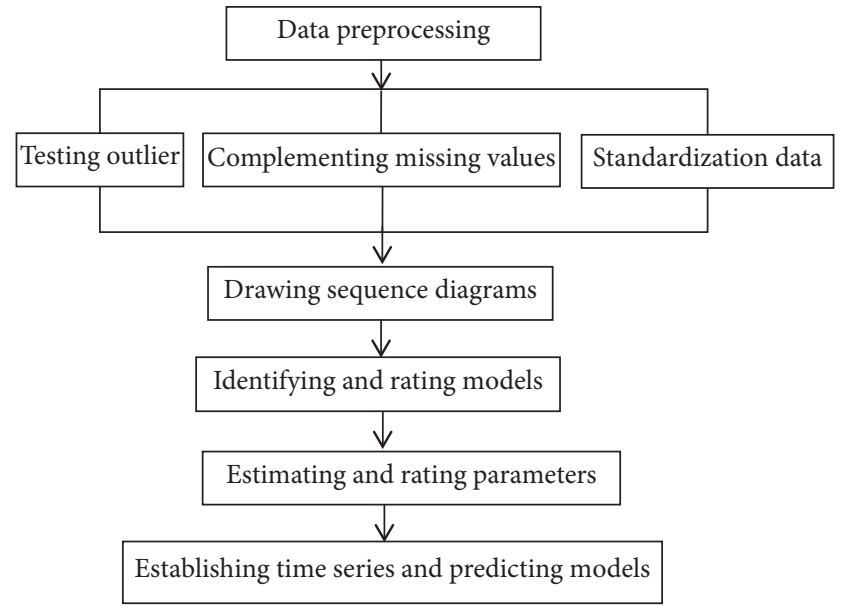

FIGURE 3: Modeling steps of time-series prediction.

elimination of outliers, and supplementation of missing values.

In order to eliminate the influence of the scale of the bridge structure on the routine engineering quantity data of the $\mathrm{RC}$ beam bridge and according to the relationship between details and the length and width of the bridge, unitization of routine maintenance in each detail is as follows. The routine maintenance related to the length and width of bridges is divided by the product of the bridge length and the number of lanes, for example, the replacement of expansion joints. The amount of routine maintenance related only to the length of the bridge is divided by the length of the bridge, for example, the maintenance of steel handrails.

In time-series analysis, due to the limitation of actual sample size, the representative value of one year's routine maintenance is divided into four seasons' data, which not only meets the sample size requirements predicted by the time series but also conforms to the actual situation of quarterly payment and settlement in the project.

Aggregating the actual data, this paper describes the performance of time-series analysis on three routine maintenance items: replacement of expansion joints, concrete repair of expansion joints, and maintenance of steel handrails. 
TABLE 4: Sample sequence stability test.

\begin{tabular}{lcccccc}
\hline Items & $N$ & $N_{1}$ & $N_{2}$ & $r$ & $E(r)$ & $\sqrt{D(r)}$ \\
\hline Replacement of expansion joints & 36 & 12 & 24 & 12 & 17 & 2.62 \\
Repair of expansion joint concrete & 40 & 18 & 22 & 17 & 20.80 & 3.09 \\
Maintenance of steel handrails & 44 & 21 & 23 & 18 & 22.95 & 3.27 \\
\hline
\end{tabular}

$N$ is time-series length; $N_{1}$ is the number of values greater than the average of the time series; $N_{2}$ is the number of values less than the average of time series; $r$ is the total number of run lengths of the sequence; $E(r)=\left(2 N_{1} N_{2} / N\right)+1 ; D(r)=\left(\left(2 N_{1} N_{2}\left(2 N_{1} N_{2}-N\right)\right) /\left(N^{2}(N-1)\right)\right)$; Zis the test statistics; $Z=((r-E(r)) /(\sqrt{D(r)})) ;|Z|<1.96$.

(2) Data Verification. (1) Stationarity Test. The run length method is used to test the stationarity of the sample data, and the test results are used as the basis for selecting the appropriate model. Results are shown in Table 4.

Given the significance level $\alpha=0.05$ and that the values of $|Z|$ in Table 4 are all less than 1.96, the selected sample sequences all meet the stationarity requirements.

(2) Pure Randomness Test. The purpose of the pure randomness test is to judge the interdependence of sample sequence data according to the hypothesis significance test, so as to determine whether there is research value in modeling analysis. If the sample sequence is a nonpure random sequence, it shows that the sequence has the value of further analysis. The test results are shown in Table 5.

After the pure randomness test, the significance $p$ of the chi-squared test for each sample sequence in Table 5 is less than 0.05 , so all sequences are nonpure randomness sequences.

(3) Model Identification and Rating. For the tested data, the sequence diagram is drawn to determine whether there are singularities and, if so, make corrections.

The BIC criterion is a method for determining the order of the best criterion function in a time-series analysis. According to the BIC minimum criterion and combining with the autocorrelation function graph and partial autocorrelation function graph of the sample sequence, the model is selected and the order of the model is determined. Through optimization and adjustment, it was finally determined that the time-series models of the three routine maintenance cases were all first-order $\operatorname{AR}(p)$ models.

(4) Parameter Estimation and Testing. The maximum likelihood method was used to estimate the model parameters, and the significance test was performed on the parameters. The results are shown in Table 6.

Through the test, the $t$-test significance $p$ of all model parameters given in Table 6 is less than 0.05, and the autocorrelation test results of the residuals all meet the requirements, so the model passes the test.

(5) Time-Series Prediction. According to the time-series model, the various routine maintenance quantities of 8 seasons in total in 2016 and 2017 were predicted, and the reliability of the model was verified with the actual values. The results are shown in Table 7 . The difference in the table is the difference between the forecasted value and the actual values.

It can be seen from Table 7 that the differences between the predicted values of the three engineering quantities and the actual values are small. In particular, the predicted value
TABle 5: Sample sequence pure randomness test.

\begin{tabular}{lcccc}
\hline Items & To lag & Chi-squared & Freedom & $p$ \\
\hline $\begin{array}{l}\text { Replacement of } \\
\text { expansion joints }\end{array}$ & 6 & 18.65 & 6 & 0.0048 \\
$\begin{array}{l}\text { Repair of expansion } \\
\text { joints concrete }\end{array}$ & 6 & 29.62 & 6 & $<0.0001$ \\
$\begin{array}{l}\text { Maintenance of steel } \\
\text { handrails }\end{array}$ & 6 & 32.25 & 6 & $<0.0001$ \\
\hline
\end{tabular}

$p$ is the significance of the chi-squared test in a pure random test.

TABLE 6: Model parameter estimation and significance test.

\begin{tabular}{lccc}
\hline Items & Parameters & $\begin{array}{c}\text { Estimated } \\
\text { value }\end{array}$ & $p$ \\
\hline Replacement of expansion & $\mathrm{MU}$ & 429.58 & 0.0022 \\
joints & $\mathrm{AR}(1,1)$ & 0.54 & 0.0002 \\
Repair of expansion joints & $\mathrm{MU}$ & 40.35 & 0.0006 \\
concrete & $\mathrm{AR}(1,1)$ & 0.63 & $<0.0001$ \\
Maintenance of bridge steel & $\mathrm{MU}$ & 756.45 & 0.0001 \\
handrails & $\mathrm{AR}(1,1)$ & 0.63 & $<0.0001$ \\
\hline
\end{tabular}

$\mathrm{MU}$ is means of a sequence of samples; $\operatorname{AR}(1,1)$ is the coefficient of the autoregressive parameter term; $p$ is significance of the $t$-test for parameter estimation.

TABLE 7: Comparison of predicted and actual values of each item.

\begin{tabular}{|c|c|c|c|c|}
\hline \multirow[b]{2}{*}{ Items } & \multirow[b]{2}{*}{ Year } & \multicolumn{3}{|c|}{ Quantities } \\
\hline & & $\begin{array}{l}\text { Predicted } \\
\text { value }\end{array}$ & $\begin{array}{c}\text { Actual } \\
\text { value }\end{array}$ & $\begin{array}{l}\text { Absolute } \\
\text { value } \\
\text { difference }\end{array}$ \\
\hline $\begin{array}{l}\text { Replacement of } \\
\text { expansion joints } \\
(\mathrm{m} / \mathrm{km} \text {-lane) }\end{array}$ & 2016 & 2.26 & 2.37 & -0.11 \\
\hline $\begin{array}{l}\text { Repair of expansion joints } \\
\text { concrete } \\
\left(\mathrm{m}^{3} / \mathrm{km} \text {-lane }\right)\end{array}$ & 2017 & 0.15 & 0.13 & 0.02 \\
\hline Maintenance of bridge & 2016 & 2.04 & 1.58 & 0.46 \\
\hline steel handrails $(\mathrm{m} / \mathrm{km})$ & 2017 & 2.87 & 2.09 & 0.78 \\
\hline
\end{tabular}

of the concrete repair of expansion joints in 2017 is in good agreement with the actual value, and the absolute error is only 0.02 . Thus, it can be seen that the prediction results of the time-series model is in accordance with engineering practice, and the deviation from the actual data is within a reasonable range, which indicates that the model is feasible.

\section{Conclusions}

Reasonable determination of expressway routine maintenance cost is an important issue in highway asset 
management. Previous studies have mainly focused on the routine maintenance of pavement assets. In order to explore the cost model of the routine maintenance of bridge assets, in this study, we applied hierarchical regression analysis to interpretative regression analysis. This paper relies upon the historic data of $518.254 \mathrm{~km}$ of RC beam bridges from 11 expressways managed by the Shaanxi Province Transportation Group in China. Two kinds of routine maintenance cost prediction models of RC beam bridge assets based on the combination of quantity and price, and on the separation of quantity and price, were obtained.

The research basis of this paper is the preprocessing of the dependent and independent variables. Preprocessing mainly involves taking the logarithm, virtualizing the category-type independent variables, classifying the independent variable groups, and ordering the entrance hierarchical regression. Analysis results show that the maintenance cost of $\mathrm{RC}$ beam bridge assets is only affected by bridge age.

The influencing factors analysis results were used to calculate the routine maintenance expenditures of a $\mathrm{RC}$ beam bridge. A forecasting model of a combination of quantity and price was put forward, based on the principle of nonlinear regression and a forecasting model of routine maintenance amount based on the principle of a time series and the idea of the separation of quantity and price. The engineering examples were verified. The results showed that the forecasted values of the two forecasting methods are highly correlated with the actual values, and the differences between the forecasted values and the actual ones were of no statistical significance.

The research conclusion has important practical application value for improving the accuracy of the cost calculation of routine maintenance of $\mathrm{RC}$ beam bridges in Shaanxi Province and also for improving the cost calculation module and data module processing method of the bridge maintenance management system.

As the research conclusions in this paper were obtained based on the maintenance data of RC beam bridges of expressways in Shanxi Province, whether the results can be applied directly to other provinces should be verified. Other provinces can adopt the method in this paper to determine the appropriate influencing factors to calculate the expenditures.

\section{Data Availability}

The data used to support the findings of this study are included within the article.

\section{Conflicts of Interest}

The authors declare that there are no conflicts of interest regarding the publication of this paper.

\section{Acknowledgments}

This work is part of a research project on "Research on the Annual Consumption Index of Routine Maintenance of Highway," funded by the Shaanxi Provincial Department of
Transportation under Grant no. 16-34k and the Central University Basic Research Business Funding Project under Grant no. 300102218112. Data support was provided by the Shaanxi Provincial Communications Group Corporation. Their support is gratefully acknowledged.

\section{References}

[1] T. F. Fwa, K. C. Sinha, and J. D. N. Riverson, "Highway routine maintenance programming at network level," Journal of Transportation Engineering, vol. 114, no. 5, pp. 539-554, 1988.

[2] T. F. Fwa, C. Y. Tan, and W. T. Chan, "Road-maintenance planning using genetic algorithms. II: analysis," Journal of transportation engineering, vol. 120, no. 5, pp. 710-722, 1994.

[3] Y. M. Wu and J. Chang, "Study on life cycle cost model of existing bridges based on maintenance management system," Journal of Suzhou University of Science and Technology: Engineering and Technology, vol. 23, no. 1, pp. 44-49, 2010.

[4] J. L. Smith, "Life-cycle cost analysis of reinforced concrete bridges rehabilitated with CFRP," Theses and DissertationsCivil Engineering, 2015, https://uknowledge.uky.edu/ce_etds/ 33.

[5] Z. J. Song, Research on Information Management of Integrated Construction and Maintenance of Highway Bridge, Southeast University, Nanjing, China, 2015.

[6] Y. H. Dong, The Research of Bridge Maintenance Management System, Chang'an University, Xi'an, China, 2014.

[7] N. M. Okasha and D. M. Frangopol, "Computational platform for the integrated life-cycle management of highway bridges," Engineering structures, vol. 33, no. 7, pp. 2145-2153, 2011.

[8] G. Barone and D. M. Frangopol, "Life-cycle maintenance of deteriorating structures by multi-objective optimization involving reliability, risk, availability, hazard and cost," Structural Safety, vol. 48, pp. 40-50, 2014.

[9] W. Woldemariam, J. Murillo-Hoyos, and A. M. Samuel Labi, "Estimating annual maintenance expenditures for infrastructure: artificial neural network approach," Journal of Infrastructure Systems, vol. 22, no. 2, article 04015025, 2016.

[10] G. S. Ali, M. Volovski, S. Alqadhi, and M. Alinizzi, "Estimation of annual repair expenditure for interstate highway bridges," Infrastructure Asset Management, vol. 6, no. 1, pp. 40-47, 2019.

[11] M. Moloney, T. McKenna, K. Fitzgibbon, and E. McKeogh, "Quality data for strategic infrastructure decisions in Ireland," Infrastructure Asset Management, vol. 4, no. 2, pp. 40-49, 2017.

[12] A. Adetola and J. Goulding, "Collaborative framework for road infrastructure management," Infrastructure Asset Management, vol. 3, no. 2, pp. 71-80, 2016.

[13] A. Taggart, L. Tachtsi, M. Lugg, and H. Davies, "UKRLG framework for highway infrastructure asset management," Infrastructure Asset Management, vol. 1, no. 1, pp. 10-19, 2014.

[14] M. Irfan, M. B. Khurshid, A. Ahmed, and S. Labi, "Scale and condition economies in asset preservation cost functions: case study involving flexible pavement treatments," Journal of Transportation Engineering, vol. 138, no. 2, pp. 218-228, 2012.

[15] "Estimating cost per lane mile for routine highway operations, and maintenance," Project 07-12, Midwest Regional University Transportation Center, University of Wisconsin, Madison, WI, USA, 2011.

[16] B. T. Adey, B. García de Soto, and C. Senn, "Evaluating the operation and routine maintenance of municipal roads in 
Switzerland," Infrastructure Asset Management, vol. 4, no. 3, pp. 96-108, 2017.

[17] A. Al-Mansour and K. C. Sinha, "Economic analysis of effectiveness of pavement preventive maintenance," Transportation Research Record, vol. 1442, 1994.

[18] P. Lu and D. Tolliver, "Multiobjective pavement-preservation decision making with simulated constraint boundary programming," Journal of Transportation Engineering, vol. 139, no. 9, pp. 880-888, 2013.

[19] M. Hagood, Highway Routine Maintenance Cost Estimation for Nevada, University of Nevada, Las Vegas, NV, USA, 2014.

[20] R. Gibby, R. Kitamura, and H. Zhao, "Evaluation of truck impacts on pavement maintenance cost," Transportation Research Record, vol. 1262, pp. 48-56, 1990.

[21] M. Volovski, J. Murillo-Hoyos, T. U. Saeed, and S. Labi, "Estimation of routine maintenance expenditures for highway pavement segments: accounting for heterogeneity using random-effects models," Journal of Transportation Engineering, Part A: Systems, vol. 143, no. 5, p. 04017006, 2017.

[22] Z. W. Qiu, M. J. Feng, and L. J. Li, "Research on calculation methods of highway maintenance funds," Road Construction Machinery and Construction Mechanization, vol. 27, no. 4, pp. 55-56, 2010.

[23] C. L. Wu, Research on Estimation Model of Highway Asphalt Pavement Maintenance Cost Based on Target Maintenance Cycle, Chongqing Jiao tong University, Chongqing, China, 2016.

[24] S. A. Ola and I. A. Ugiomoh, "Cost of road maintenance in developing countries," Journal of Transportation Engineering, vol. 112, no. 4, pp. 440-445, 1986.

[25] R. Yue, Research of Maintenance Amount Prediction on the Highway with Intelligent Algorithm, Department of Computer Science and Technology, Wuhan Univ. of Technology, Wuhan, China, 2015.

[26] C. X. Zhang and W. Wang, "Study on the method of determining preventive maintenance time for bridges based on optimal cost effectiveness," Highway, vol. 7, pp. 159-162, 2013.

[27] J. G. Qiao and H. X. Hou, "Study on optimization of bridge transformation plan based on life cycle cost," Journal of China and Foreign Highway, vol. 34, no. 5, pp. 93-95, 2014.

[28] S. Kubota and I. Mikami, "Development of product data model for maintenance in concrete highway bridges," Applied Computational Intelligence and Soft Computing, vol. 2013, Article ID 148785, 12 pages, 2013.

[29] I.-C. Wu and S.-H. Hsieh, "A framework for facilitating multidimensional information integration, management and visualization in engineering projects," Automation in Construction, vol. 23, pp. 71-86, 2012.

[30] D. M. Frangopol, Y. Dong, and S. Sabatino, "Bridge life-cycle performance and cost: analysis, prediction, optimisation and decision-making," Structure and Infrastructure Engineering, vol. 13, no. 10, pp. 1239-1257, 2017.

[31] Y. Zhang, D. A. Novick, A. Hadavi, and R. J. Krizek, "Lifecycle cost analysis of bridges and tunnels," Construction Research Congress, vol. 183, pp. 1-9, 2005.

[32] B. S. Yanev, "Bridge maintenance life cycle cost assessment," in Proceedings of the First US-Japan Workshop on Life-Cycle Cost Analysis and Design of Civil Infrastructure Systems, Honolulu, HI, USA, August 2000.

[33] K. C. Sinha, S. A. Labi, B. G. McCullouch, A. Bhargava, and Q. Bai, "Updating and enhancing the Indiana bridge management system (IBMS)," Publication FHWA/IN/JTRP-30, Joint Transportation Research Program, Indiana Department of Transportation and Purdue University, West Lafayette, IN, USA, 2009.
[34] T. Hegazy, E. Elbeltagi, and H. El-Behairy, "Bridge deck management system with integrated life-cycle cost optimization," Transportation Research Record: Journal of the Transportation Research Board, vol. 1866, no. 1, pp. 44-50, 2004.

[35] S. Labi, M. M. Rodriguez, and K. C. Sinha, "Assessing preservation needs for a bridge network: a comparison of alternative approaches," Structure and Infrastructure Engineering, vol. 4, no. 3, pp. 221-235, 2008.

[36] K. C. Sinha, S. Labi, and M. Rodriguez, "Procedures for the estimation of pavement and bridge preservation costs for fiscal planning and programming," Publication FHWA/IN/ JTRP-17, Joint Transportation Research Program, Indiana Department of Transportation and Purdue University, West Lafayette, IN, USA, 2005.

[37] J. Jebreen and D. W. Johnston, "Bridge maintenance level of service optimization based on an economic analysis approach," 1995.

[38] D. Lee, "Comparative maintenance costs of different bridge types," in Bridge Management, pp. 145-153, Springer, Boston, MA, USA, 1990.

[39] L. C. Neves and D. M. Frangopol, "Condition, safety and cost profiles for deteriorating structures with emphasis on bridges," Reliability Engineering and System Safety, vol. 89, no. 2, pp. 185-198, 2005.

[40] C. Zhou, Research on Condition Assessment of Existing Bridges and the Maintenance Managing Method, Zhejiang University, Hangzhou, China, 2008.

[41] S.-Y. Ok, S.-Y. Lee, and W. Park, "Robust multi-objective maintenance planning of deteriorating bridges against uncertainty in performance model," Advances in Engineering Software, vol. 65, pp. 32-42, 2013.

[42] F. Biondini and D. M. Frangopol, "Life-cycle performance of deteriorating structural systems under uncertainty: review," Journal of Structural Engineering, vol. 142, no. 9, article F4016001, 2016.

[43] D. Kifokeris, J. A. Campos e Matos, Y. Xenidis, and L. Bragança, "Bridge quality appraisal methodology: application in a reinforced concrete overpass roadway bridge," Journal of Infrastructure Systems, vol. 24, no. 4, article 04018034, 2018.

[44] J. L. Qin, Research on Key Technology to Bridge Maintenance Planning, Beijing University of Civil Engineering and Architecture, Beijing, China, 2014.

[45] Z. J. Hu, Study of RC Beam Bridge Condition State Assessment System Based on Al, Tongji University, Shanghai, China, 2016.

[46] G. Du, M. Safi, L. Pettersson, and R. Karoumi, "Life cycle assessment as a decision support tool for bridge procurement: environmental impact comparison among five bridge designs," The International Journal of Life Cycle Assessment, vol. 19, no. 12, pp. 1948-1964, 2014.

[47] Z. H. Zong, Z. G. Yang, Y. F. Xia, and W. W. Yuan, "Vehicle load model of Xinyihe bridge under congestion operation," China Journal of Highway and Transport, vol. 29, no. 2, pp. 44-51, 2016.

[48] W. S. Han, Y. Zhao, and H. J. Liu, "Research status and development trend of wind-vehicle-bridge coupled vibration," China Journal of Highway and Transport, vol. 31, no. 7, pp. 1-23, 2018.

[49] J. M. Wooldridge, Introductory Econometrics, China Renmin University Press, Beijing, China, 2014.

[50] H. Z. Qiu, Quantitative Research and Statistical Analysis, Chongqing University Press, Chongqing, China, 2015. 


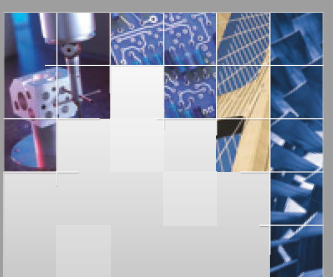

\section{Enfincering}
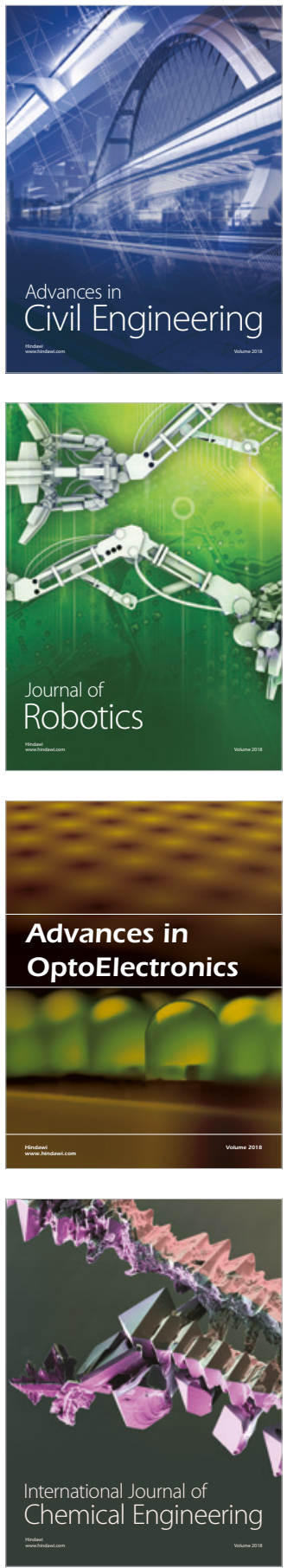

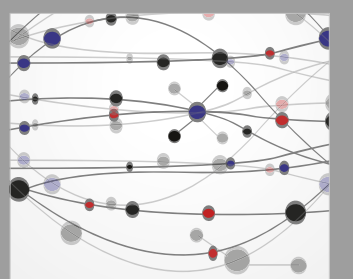

\section{Rotating \\ Machinery}

The Scientific World Journal

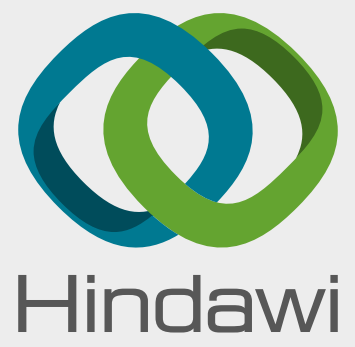

Submit your manuscripts at

www.hindawi.com
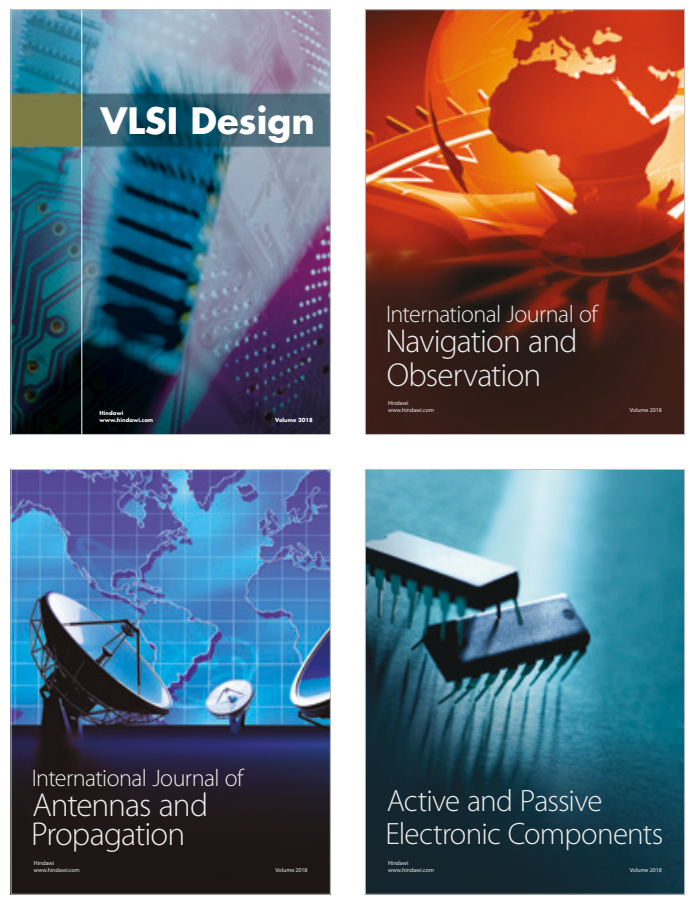
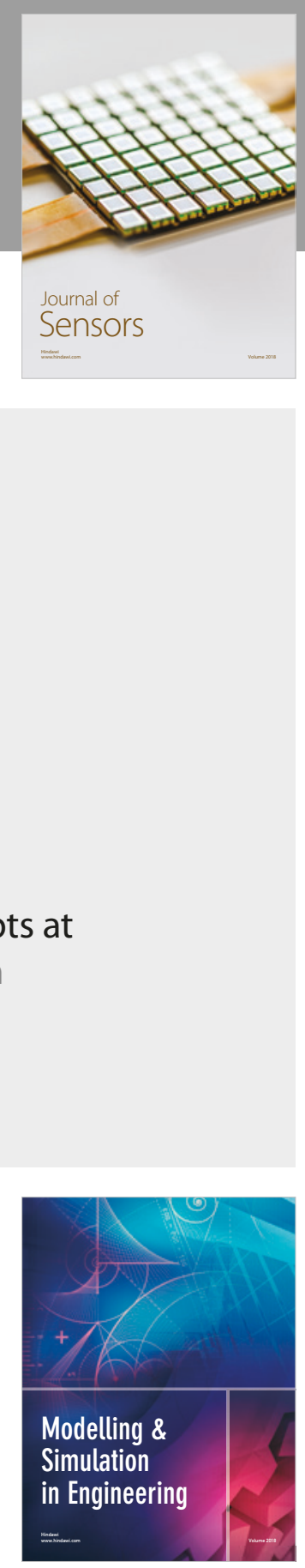

\section{Advances \\ Multimedia}
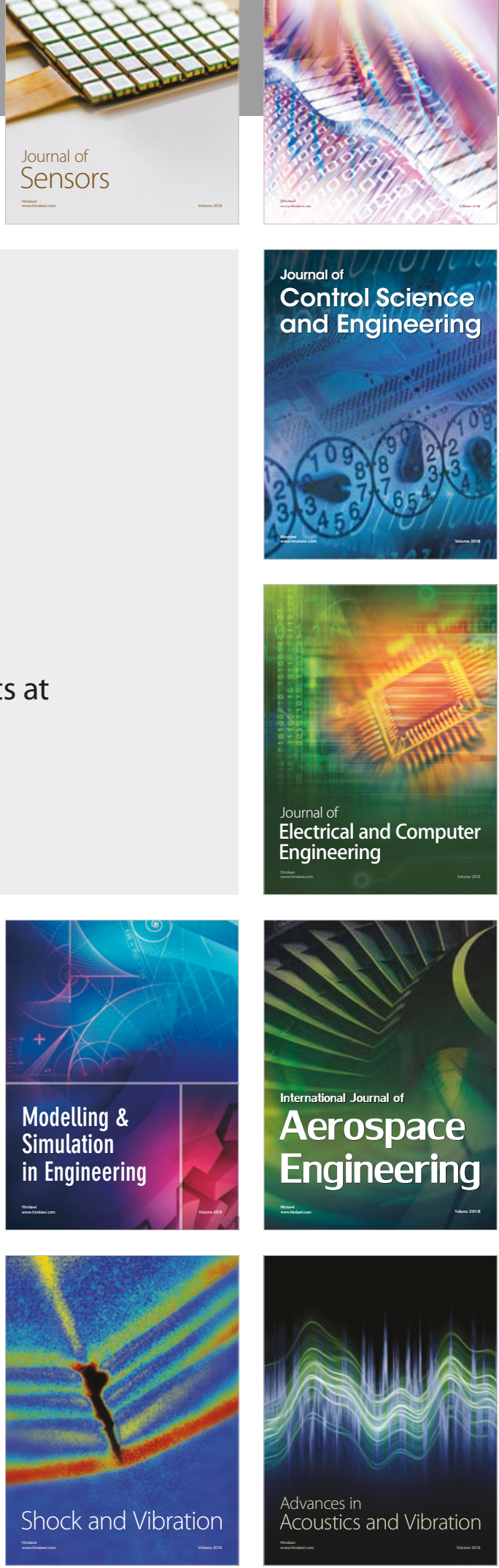